\title{
Mifepristone Decreases Chronic Voluntary Ethanol Consumption in Rhesus Macaques ${ }^{[}$
}

\author{
Vanessa A. Jimenez, Nicole A.R. Walter, Tatiana A. Shnitko, Natali Newman, Kaya Diem, \\ Lauren Vanderhooft, Hazel Hunt, and 지thleen A. Grant \\ Division of Neuroscience, Oregon National Primate Research Center, Hillsboro, Oregon N.A.J., N.A.R.W., T.A.S., N.N., K.D., \\ L.V., K.A.G.); Corcept Therapeutics, Menlo Park, California (H.H.); and Department of Behavioral Neuroscience, Oregon Health \& \\ Science University, Portland, Oregon (K.A.G.)
}

Received June 16, 2020; accepted August 17, 2020

\section{ABSTRACT}

The efficacy of short-term treatment with mifepristone (MIFE), a high-affinity, nonselective glucocorticoid receptor antagonist, to reduce ethanol drinking was tested in a rhesus macaque model. Stable individual daily ethanol intakes were established, ranging from 1.6 to $4.0 \mathrm{~g} / \mathrm{kg}$ per day ( $n=9$ monkeys). After establishment of chronic ethanol intake, a MIFE dosing regimen that modeled a study of rodent drinking and human alcohol craving was evaluated. Three doses of MIFE (17, 30, and $56 \mathrm{mg} / \mathrm{kg}$ per day) were each administered for four consecutive days. Both 30 and $56 \mathrm{mg} / \mathrm{kg}$ decreased ethanol intake compared with baseline drinking levels without a change in water intake. The dose of $56 \mathrm{mg} / \mathrm{kg}$ per day of MIFE produced the largest reduction in ethanol self-administration, with the average intake at $57 \%$ of baseline intakes. Cortisol was elevated during MIFE dosing, and a mediation analysis revealed that the effect on ethanol drinking was fully mediated through cortisol. During a forced abstinence phase, access to $1.5 \mathrm{~g} / \mathrm{kg}$ ethanol resulted in relapse in all drinkers and was not altered by treatment with $56 \mathrm{mg} / \mathrm{kg}$ MIFE. Overall, these results show that during active drinking MIFE is efficacious in reducing heavy alcohol intake in a monkey model, an effect that was related to MIFEinduced increase in cortisol. However, MIFE treatment did not eliminate ethanol drinking. Further, cessation of MIFE treatment resulted in a rapid return to baseline intakes, and MIFE was not effective in preventing a relapse during early abstinence.

\section{SIGNIFICANCE STATEMENT}

Mifepristone reliably decreases average daily ethanol selfadministration in a nonhuman primate model. This effect was mediated by cortisol, was most effective during open-access conditions, and did not prevent or reduce relapse drinking.

\section{Introduction}

Approximately 14.8 million people in the United States, or 1 in 19, had an alcohol use disorder (AUD) in 2018 (https://www. samhsa.gov/data/). The prevalence of a lifetime diagnosis of AUD between 2012 and 2013 was $29.1 \%$, a substantial increase from 2001 to 2002, with fewer than 20\% seeking treatment (Grant et al., 2015). The Food and Drug Administration has approved three medications for the treatment of AUD between 1951 and 2006: disulfiram, oral and extended release naltrexone, and acamprosate. Two additional drugs, topiramate and gabapentin, are recommended for the off-label treatment of AUD by the American Psychiatric Association (Reus et al., 2018), and a number of other treatments are under investigation (Litten et al., 2015; Swift and Aston, 2015; Witkiewitz et al., 2019). A major challenge in the development

This work was supported by National Institutes of Health National Institute of Alcoholism and Alcohol Abuse [Grants AA019431, AA013510, AA013641] (to K.A.G.).

H.H. is an employee at Corcept Therapeutics.

https://doi.org/10.1124/jpet.120.000169.

S This article has supplemental material available at jpet.aspetjournals.org. of successful pharmacologic intervention is that AUD is a highly heterogeneous disorder with multiple biologic and environmental factors (Litten et al., 2015). In fact, the efficacy of currently approved medications can be related to neurobiologic features present in subsets of individuals diagnosed with AUD (Litten et al., 2015; Witkiewitz et al., 2019). The heterogeneity of AUD and the interaction with specific pharmacotherapies highlight both the need and challenge of developing treatment options that target subsets of individuals.

Pharmacotherapies that target the stress system are a promising avenue for novel interventions. The hypothalamic pituitary adrenal (HPA) axis is a fundamental system in maintaining homeostasis and is disrupted by long-term ethanol consumption and abstinence in humans and animals (Becker, 2012; Blaine et al., 2017; Jimenez and Grant, 2017). Cortisol, the primary glucocorticoid secreted by the adrenal cortex, is a primary endpoint of HPA axis activation. The HPA axis response to stress (psychologic and pharmacologic) is blunted in alcohol-dependent subjects relative to nonalcoholic controls (Lovallo et al., 2000; Adinoff et al., 2005a,b), although cortisol is elevated during ethanol withdrawal (Iranmanesh

ABBREVIATIONS: AUD, alcohol use disorder; BEC, blood ethanol concentration; $\mathrm{Cl}$, confidence interval; GR, glucocorticoid receptor; HPA, hypothalamic pituitary adrenal axis; MIFE, mifepristone; MR, mineralocorticoid receptor; PVN, paraventricular nucleus of the hypothalamus; RM-ANOVA, Repeated measures analysis of variance. 
et al., 1989; Adinoff et al., 1991, 2003). Furthermore, stress is a salient risk factor for relapse (Blaine and Sinha, 2017), suggesting treatments that target the HPA response may be efficacious in treating AUD. An antagonist at the glucocorticoid receptor, mifepristone (MIFE), has been tested in a variety of preclinical models of AUD. In rodents, MIFE shows efficacy on a large number of alcohol phenotypes, including blocking ethanol-induced place preference (Rotter et al., 2012), reducing ethanol intake (Koenig and Olive, 2004; Vendruscolo et al., 2012, 2015), reducing cognitive deficits in ethanol withdrawal (Jacquot et al., 2008), protecting hippocampal neurons from injury due to binge-like ethanol consumption (Cippitelli et al., 2014), reducing ethanol withdrawal severity (Sharrett-Field et al., 2013), reducing stressinduced reinstatement of ethanol seeking (Simms et al., 2012), and decreasing the escalation of alcohol self-administration after protracted abstinence (Repunte-Canonigo et al., 2015).

Nonhuman primates are less represented in preclinical studies of ethanol pharmacotherapy evaluation (Weerts et al., 2007). Rhesus monkeys are an excellent model for studies of individual differences in propensity to drink large amounts of alcohol associated with an AUD diagnosis and biomedical consequences (>8-12 drink equivalent/day) (Baker et al., 2014) and stress-related interventions because of their similar endocrine physiology with humans, particularly adrenal physiology (Conley et al., 2004; Jimenez and Grant, 2017). In this study, we tested the effect of a 4-day oral MIFE administration on the ability to reduce ethanol intake and blood ethanol concentrations (BEC) in rhesus monkeys with a history of daily open-access to ethanol self-administration ( 22 hours/day) and to determine whether drinking would return to baseline intakes after the cessation of MIFE treatment. We further investigated whether a 3-day MIFE treatment could prevent relapse drinking during forced abstinence.

\section{Methods}

Animals. Twelve adult male rhesus macaques (Macaca mulatta) were assigned as ethanol drinkers $(n=9)$ or ethanol-naïve controls $(n=3)$. Animals were housed in quadrant cages $(0.8 \times 0.8 \times 0.9 \mathrm{~m})$ with constant temperature $\left(20-22^{\circ} \mathrm{C}\right)$ and humidity $(65 \%)$ and an 11 -hour light cycle (lights on at 07:00). Animals had visual, auditory, and olfactory contact with other animals in the protocol. All animals were maintained on a positive caloric and fluid balance throughout the experiment, and body weights were recorded weekly. Monkeys were $5.6-5.8$ years of age at the start of open-access conditions. Other data that have been collected and/or published on this cohort of animals (Rhesus 14) can be found through the Monkey Alcohol and Tissue Research Resource (www.MATRR.com) (Daunais et al., 2014). All procedures were conducted in accordance with the Guide for the Care and Use of Laboratory Animals and the National Institutes of Health guidelines for the care and use of laboratory animal resources and approved by the Oregon National Primate Research Center Institutional Animal Care and Use Committee.

Operant Panel. Operant panels dispense food and fluids, as previously described (Grant et al., 2008; Shnitko et al., 2019, 2020). Briefly, each panel has two spouts, each below a set of three stimulus lights (white, red, and green) that indicate an active session, food, or fluid availability, respectively. A centrally located recessed dowel activates the fluid spouts, and an infrared finger poke activates the pellet dispenser. Dowel pulls, finger pokes, and fluid consumption are recorded in real time (approximately every 500 milliseconds) using custom hardware and programing using National Instruments interface and Labview software. Operant panels ran daily from 11: 00 to 09:00 (the next morning). Between 09:00 and 11:00 each day, operant panels were turned off while data were downloaded, husbandry tasks were performed, food and fluids were replenished, and enrichment was provided.

Ethanol Induction. A schedule-induced polydipsia procedure was used to induce ethanol self-administration in daily 16-hour sessions, as previously described (Vivian et al., 2001; Grant et al., 2008). Briefly, a 1-g banana food pellet was delivered every 300 seconds until a water volume equivalent to $1.5 \mathrm{~g} / \mathrm{kg}$ of $4 \%(\mathrm{w} / \mathrm{v})$ ethanol was consistently consumed in the interpellet interval. After water induction, 4\% ethanol replaced water. In approximately 30-day increments, each animal consumed increasing daily doses of $4 \%$ ethanol: $0.5 \mathrm{~g} / \mathrm{kg}$ per day, $1.0 \mathrm{~g} / \mathrm{kg}$ per day, and then $1.5 \mathrm{~g} / \mathrm{kg}$ per day. After consumption of the ethanol dose, water was immediately available, and any remaining pellets were available on a fixed-ratio-1 schedule after a 2-hour delay.

Ethanol Self-Administration and Forced Abstinence. After $1.5 \mathrm{~g} / \mathrm{kg}$ per day ethanol induction, open-access ethanol self-administration began, in which water and ethanol were concurrently available in daily 22-hour sessions. Starting at the session onset, food pellets (up to one-third of the daily ration) were available on a fixed-ratio-1 schedule in at least three daily meals with 2-hour intervals between meals. A meal ended when one-third of the daily food allotment was obtained or if the monkey took longer than 2 minutes to obtain a pellet. Between meals, red stimulus lights above the spouts signaled a 2-hour time-out, during which food pellets were not available.

After 467 consecutive daily open-access alcohol sessions, the animals entered the first forced abstinence phase. During abstinence, the stimuli on the operant panel were identical to openaccess conditions, with the only change being that the ethanol reservoir was replaced with water. The abstinence phases lasted 34,41 , and 39-46 days (variable because of the timing of necropsy), respectively. After the first and second abstinence phases were two open-access phases lasting 76 and 104 days, respectively. The experimental timeline is shown in Fig. 1A.

Control Subjects. Ethanol-naïve control subjects were housed in the same room as the ethanol-drinking subjects and participated in all experimental manipulations (blood collections, MIFE, etc). Scheduleinduced polydipsia and self-administration conditions were identical, with the exception that both spouts dispensed water. A maltosedextran solution ( $10 \%$ in water) was given to the controls to calorically match the drinkers and controls. Each control subject was yoked to an ethanol drinker of similar body weight. Each week, the average daily calories consumed from ethanol was calculated to make an isocaloric maltose-dextrin solution for the yoked control animal. Maltosedextrin was given at the beginning of each daily session by attaching a bottle to the front of the housing cage beginning in $0.5 \mathrm{~g} / \mathrm{kg}$ per day induction. Maltose-dextrin was not available during abstinence.

Blood Samples. Femoral blood samples were obtained with a 22-g $\times 1$-inch Vacutainer needle and a 3-ml Vacutainer hematology tube (Becton Dickinson, Franklin Lakes, NJ). All blood samples were stored on ice ( $\sim 15$ minutes) until centrifuged ( $3000 \mathrm{rpm}, 15$ minutes at $4^{\circ} \mathrm{C}$, Model Allegra 21R; Beckman Coulter, Fullerton, CA). Plasma samples $\left(300-\mu \mathrm{l}\right.$ aliquots) were frozen at $-80^{\circ} \mathrm{C}$ until processing.

BEC was measured by collecting blood $(20 \mu \mathrm{l}) 7$ hours into the drinking session, approximately once per week. Whole blood was placed into airtight containers and stored at $-4^{\circ} \mathrm{C}$ until assayed using headspace gas chromatography (Agilent Technologies, Santa Clara, CA) and analyzed using linear regression and a standard curve ranging from 25 to $400 \mathrm{mg} / \mathrm{dl}$.

Mifepristone Administration. Mifepristone (Corcept Therapeutics, Menlo Park, CA) powder was prepared for oral consumption in fruit tape wrapping, a peanut butter ball, or an apple with honey and peanut butter. Three doses (17, 30, and $56 \mathrm{mg} / \mathrm{kg}$ per day) were tested during open access ( 22 hour/day) to ethanol, each for four consecutive days. MIFE was given at approximately 10:00 each morning, during the 2 -hour window when ethanol was not available. The $56 \mathrm{mg} / \mathrm{kg}$ dose 


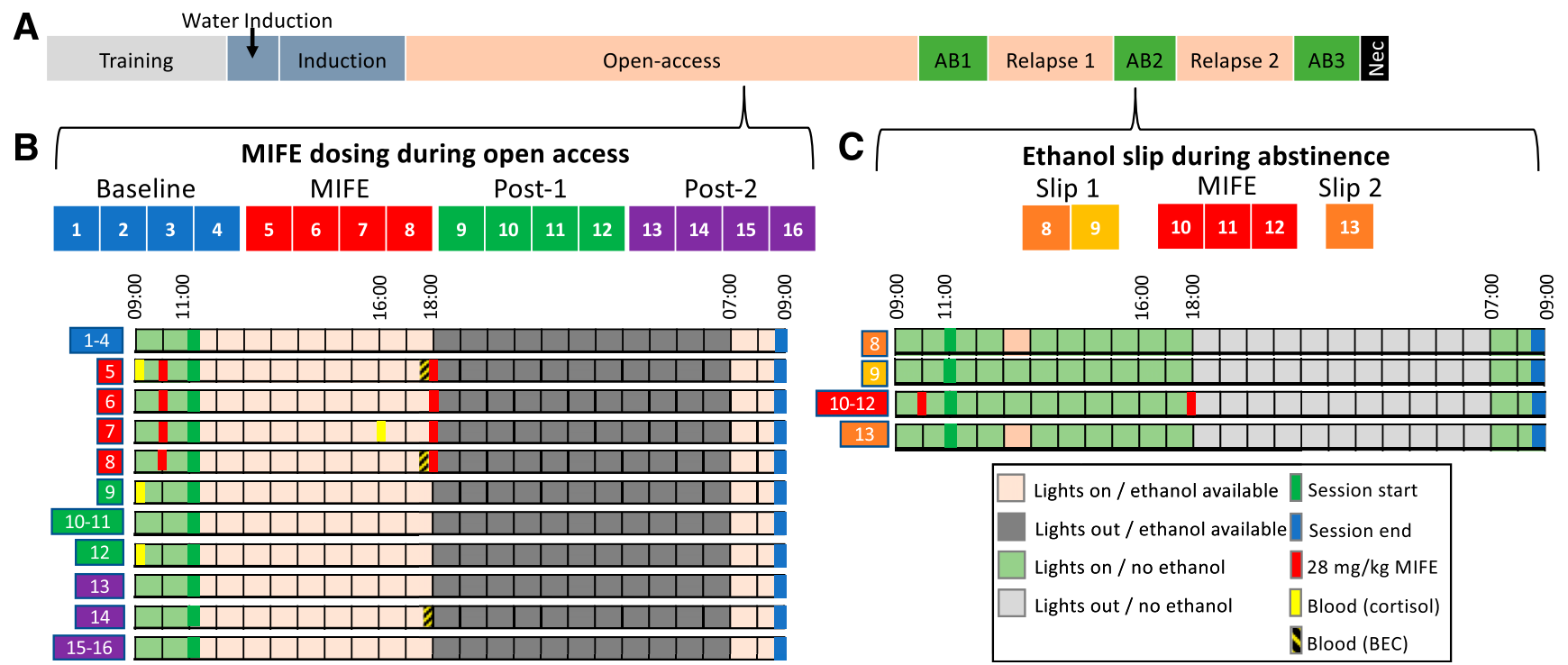

Fig. 1. Experimental timeline and MIFE administration. (A) Complete experimental timeline. (B) The dosing regimen occurred in a 16-day cycle, divided into four experimental phases, which are referred to by dosing day throughout the results. Detailed hour-by-hour timeline during $56 \mathrm{mg} / \mathrm{kg}$ per day MIFE dosing in open access. (C) A dose of $1.5 \mathrm{~g} / \mathrm{kg}$ ethanol was available on the 8 th day of the second abstinence phase, 2 hours into the daily session, and again on the 13th day of abstinence after 3 days of $56 \mathrm{mg} / \mathrm{kg}$ per day MIFE. Note the phases, days, and colors shown in (B and C) are used in the following figures. AB1, first forced abstinence; AB2, second forced abstinence; Nec, necropsy.

was administered as two doses of $28 \mathrm{mg} / \mathrm{kg}$, with the second daily dose given at 18:00, right before the lights went off. A detailed timeline of the $56 \mathrm{mg} / \mathrm{kg}$ MIFE administration is provided in Fig. 1B. MIFE dosing during open access was evaluated across a 16-day dosing regimen, including 4 days of baseline (days 1-4; blue), 4 days of MIFE (days 5-8; red), first 4 days of post-MIFE (days 9-12; Post-1; green), and second 4 days of post-MIFE (days 13-16; Post-2; purple) (see Fig. 1B). These bins were used for statistical analyses. The 17 and $30 \mathrm{mg} / \mathrm{kg}$ per day timelines varied from the $56 \mathrm{mg} / \mathrm{kg}$ timeline in that MIFE was given once each day (10:00 AM). There was no afternoon blood draw on day 7 after $17 \mathrm{mg} / \mathrm{kg} \mathrm{MIFE}$, and the $30 \mathrm{mg} / \mathrm{kg}$ had an afternoon blood draw at 16:00 rather than 18:00 on day 7 .

Both controls and drinkers were given MIFE. The amount of time to consume a particular dose varied by animal. Overall, MIFE was reliably consumed. Among individuals, there were no more than three occasions per dose in which MIFE was only partially consumed (for example, a small amount observed on the floor of the cage). In these instances, the delivery method was changed (for example, from a peanut butter ball to a fruit tape pouch) for the following dose to increase compliance. During abstinence, noncompliance remained low, with no more than two suspected partial doses per animal. One animal was excluded from analysis because of its having partially consumed or refused more than half the doses (animal 10243). There was a washout period of at least 10 days between doses during open access, and there were 222 days between the last MIFE dose during open access and abstinence.

Ethanol Relapse and Mifepristone during Abstinence. To test the effect of MIFE on reducing individual differences in the vulnerability to relapse, 1 week after the beginning of the second abstinence phase (abstinent day 8), a single dose of $1.5 \mathrm{~g} / \mathrm{kg}$ ethanol was made available 2 hours after the session began (Fig. 1C). On abstinent days $10-12,56 \mathrm{mg} / \mathrm{kg}$ MIFE was administered, as previously described. On abstinent day 13 , the monkeys were again given access to $1.5 \mathrm{~g} / \mathrm{kg}$ ethanol. We evaluated the rate of intake and preference before and after the MIFE dosing regimen. The rate of drinking was defined as the time elapsed between the first drink and the completion of $1.5 \mathrm{~g} / \mathrm{kg}$. Preference was defined as the volume (milliliter) of ethanol consumed divided by the total volume (ethanol + water) consumed during the time to reach the cutoff of $1.5 \mathrm{~g} / \mathrm{kg}$.

Mifepristone Assay. Monkey plasma samples containing mifepristone and D4-mifepristone (internal standard) were extracted using a mixture of hexane and methyl-tert-butyl ether. The organic layer was evaporated to dryness under nitrogen, and the residue was reconstituted in water/acetonitrile/formic acid (75:25:0.1, v/v/v). The sample extracts were analyzed by reversed phase chromatography using a Zorbax SB-phenyl column maintained at $50^{\circ} \mathrm{C}$. The mobile phase was nebulized using a heated nitrogen in a Z-spray source/ interface, and the ionized compounds were detected using a tandem quadrupole mass spectrometer.

Hormone Assays. Plasma aliquots were assayed by the Endocrine Technology Core at Oregon National Primate Research Center (Beaverton, OR). A Roche Cobas e411 automatic clinical platform was used to assay cortisol (0.036-63.4 $\mu \mathrm{g} / \mathrm{dl}$ sensitivity).

Statistical Methods. A two-way repeated measures (RM) ANOVA was used to detect differences in the concentration of MIFE using group (control vs. drinker) and time (day 7 vs. day 9) as factors. The effect of MIFE on ethanol and water intake were analyzed using a repeated measures mixed-effects model with time (two levels: baseline, MIFE), dose (three levels: 17, 30, and $56 \mathrm{mg} / \mathrm{kg}$ ), and group (for water analysis) as independent variables. Repeated measures ANOVAs were used to determine whether the effects of 30 and $56 \mathrm{mg} / \mathrm{kg}$ MIFE persisted after dosing ended and their effects on circulating cortisol concentration using phase (four levels: baseline, MIFE, Post-1, and Post-2) as the independent variable. The effects of MIFE during abstinence were evaluated by comparing the rate of ethanol intake and preference between the two ethanol challenges (as described above) using repeated measures ANOVA. Significant results are reported based on post hoc comparisons using Bonferroni corrected $t$ tests. A mediation analysis of MIFE-induced cortisol on ethanol intake was performed using the "mediate" package in R (Tingley et al., 2014; https://www.R-project.org/ ). Cortisol and MIFE concentrations and the percent change in ethanol intake were log-transformed prior to the mediation analysis. All animals were included in analysis ( $n=9$ drinkers, $n=3$ controls), unless otherwise stated. Data are presented as means \pm S.D., with 95\% confidence intervals (CI). All analyses were conducted in Prism (version 8) or RStudio (version 1.2), $\alpha<0.05$.

\section{Results}

Mifepristone Plasma Concentrations. There were wide individual differences in circulating MIFE concentrations that led to large variance in average data. For the $17-\mathrm{mg} / \mathrm{kg}$ dose, 
the average concentration of MIFE the morning after the final dose (day 9) was $6.0 \pm 4.1 \mathrm{ng} / \mathrm{ml}$ [95\% CI $(3.4,8.6)]$. For $30 \mathrm{mg} / \mathrm{kg}$ per day MIFE, the average evening concentration after the third dose (day 7) was $39.3 \pm 36.1 \mathrm{ng} / \mathrm{ml}[95 \% \mathrm{CI}$ $(16.4,62.3)]$ and had decreased to $14.7 \pm 13.6 \mathrm{ng} / \mathrm{ml}[95 \% \mathrm{CI}$ (6.1, 23.3)] the morning after the final dose (day 9; Fig. 2A). An RM-ANOVA revealed a main effect of time $\left[\mathrm{F}_{(1,10)}=8.5, P=\right.$ 0.016 ] but not group [control vs. drinker: $\mathrm{F}_{(1,10)}=0.5, P>0.05$ ] and no interaction $\left[\mathrm{F}_{(1,10)}=0.6, P>0.05\right]$. With $56 \mathrm{mg} / \mathrm{kg}$ per day MIFE, the average evening concentration on day 7 was $259.1 \pm 203.6 \mathrm{ng} / \mathrm{ml}[95 \% \mathrm{CI}(129.7,388.4)]$ and decreased to $176.1 \pm 124.7 \mathrm{ng} / \mathrm{ml}[95 \% \mathrm{CI}(96.9,255.3)]$ the morning after the final dose (day 9; Fig. 2B). An RM-ANOVA revealed a main effect of time $\left[\mathrm{F}_{(1,10)}=5.2, P=0.046\right]$ but not group $\left[\mathrm{F}_{(1,10)}=\right.$ $0.03, P>0.05]$ and no interaction $\left[\mathrm{F}_{(1,10)}=0.8, P>0.05\right]$.

Mifepristone Effect on Ethanol and Water Intake in Open-Access Availability. By 6 months of daily ethanol self-administration (151-153 consecutive open-access sessions), average daily ethanol intake ranged from 1.64 to $4.02 \mathrm{~g} / \mathrm{kg}$ per day The average BEC across 30 to 31 samples ranged from 23 to $135 \mathrm{mg} / \mathrm{dl}$. These intakes and BECs represent a stage of ethanol intake when between-subject daily drinking patterns are predictable and demonstrate this cohort had two light drinkers, one binge drinker, four heavy drinkers, and two very heavy drinkers, as previously defined (Baker et al., 2014). MIFE testing began on the 223rd day of open access and continued until the 331st day of open access (see Fig. 1A).

Average daily ethanol and water intake was calculated during the 4 days prior to each MIFE dose (baseline) and compared with the 4-day average intake during each dose of MIFE (see Fig. 1B). The average daily intake between the three baseline phases had a coefficient of variation of less than $15 \%$ for each subject. A mixed-effects model yielded a main effect of dose $\left[\mathrm{F}_{(2,16)}=5.9, P=0.012\right]$ and phase [two levels: baseline and MIFE; $\mathrm{F}_{(1,8)}=45.2, P<0.001$ ], with lower ethanol intake during MIFE administration (Fig. 3A). The interaction was also significant $\left[\mathrm{F}_{(2,16)}=17.9, P<0.001\right]$. Post hoc comparisons revealed an effect of baseline [mean: $3.2 \mathrm{~g} / \mathrm{kg}$ per day, 95\% CI $(2.5,3.9)]$ versus $30 \mathrm{mg} / \mathrm{kg}$ per day MIFE [mean: $2.6 \mathrm{~g} / \mathrm{kg}$ per day, 95\% CI $(1.9,3.4) ; P_{\mathrm{adj}}=0.0018$ ] and baseline [mean: $3.2 \mathrm{~g} / \mathrm{kg}$ per day; $95 \%$ CI $(2.3,4.1)$ ] versus $56 \mathrm{mg} / \mathrm{kg}$ per day MIFE [mean: $1.8 \mathrm{~g} / \mathrm{kg}$ per day, $95 \% \mathrm{CI}$ (1.2, $2.5) ; P_{\text {adj }}<0.0001$ ] but no effect of the $17 \mathrm{mg} / \mathrm{kg}$ per day dose and no differences among the three baseline phases. There

A

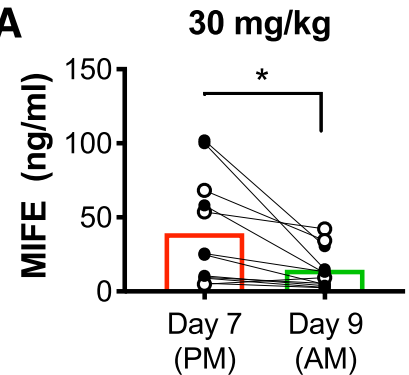

Fig. 2. MIFE concentration in plasma measured in the evening of the third daily dose (day 7) and the morning after the final dose (day 9) for $30 \mathrm{mg} / \mathrm{kg}$ (A) and $56 \mathrm{mg} / \mathrm{kg}(\mathrm{B})$. Data represent individual ( $n=9$ drinkers, filled circles; $n=3$ controls, open circles) and average (bars) MIFE concentration. Note the $y$-axis scales are not identical. ${ }^{*} P<0.05$. were differences in intake between 30 and $56 \mathrm{mg} / \mathrm{kg}$ per day $\left(P_{\mathrm{adj}}<0.001\right)$ and between 17 and $56 \mathrm{mg} / \mathrm{kg}$ per day $\left(P_{\mathrm{adj}}<\right.$ $0.001)$. These data demonstrate a MIFE dose response in which doses of 30 and $56 \mathrm{mg} / \mathrm{kg}$ per day were effective in decreasing ethanol consumption. During the 4 days of MIFE dosing, the subjects drank an average of $81 \%$ and $57 \%$ of their baseline intake levels for 30 and $56 \mathrm{mg} / \mathrm{kg}$ per day, respectively.

The effect of MIFE on water consumption was evaluated with a mixed-effects model and yielded no main effect of phase $\left[\mathrm{F}_{(5,50)}=0.5, P>0.05\right]$ or dose $\left[\mathrm{F}_{(2,50)}=2.3, P>0.05\right]$ but a main effect of group, in which controls consumed more water [controls: $151.9 \pm 9.2 \mathrm{~g} / \mathrm{kg}$ per day, $95 \% \mathrm{CI}$ (143.9, 159.8); drinkers: $92.8 \pm 14.4 \mathrm{~g} / \mathrm{kg}$ per day, $95 \% \mathrm{CI}(81.1,104.6) ; \mathrm{F}_{(1,10)}$ $=5.5, P=0.041]$. Therefore, although MIFE effectively reduced ethanol intake at both 30 and $56 \mathrm{mg} / \mathrm{kg}$ per day, water intake was not affected (Fig. 3B). No food remained at the end of the sessions, and body weights remained unchanged.

For the two effective doses of MIFE (30 and $56 \mathrm{mg} / \mathrm{kg}$ per day), the post-MIFE ethanol intakes were evaluated over the baseline, MIFE dosing, and eight sessions after the last MIFE administration, (divided into two four-session "bins", Post-1 and Post-2 (see Fig. 1B). Using an RM-ANOVA, the dose of $30 \mathrm{mg} / \mathrm{kg}$ per day had an effect on ethanol intake over time $\left[\mathrm{F}_{(1.9,15.2)}=11.0, P=0.0012\right]$. Post hoc analyses compared each 4-day bin to baseline. There was a decrease in ethanol intake from baseline to MIFE dosing [baseline: $3.2 \pm 0.3 \mathrm{~g} / \mathrm{kg}$ per day, 95\% CI (2.5, 3.9); $30 \mathrm{mg} / \mathrm{kg}$ per day MIFE: $2.6 \pm 0.3 \mathrm{~g} / \mathrm{kg}$ per day, 95\% CI $\left.(1.9,3.4) ; P_{\text {adj }}=0.0003\right]$ and from baseline to Post$2\left[2.8 \pm 0.3 \mathrm{~g} / \mathrm{kg}\right.$ per day, 95\% CI $\left.(2.0,3.5) ; P_{\mathrm{adj}}=0.0028\right]$ (Fig. 4A). The dose of $56 \mathrm{mg} / \mathrm{kg}$ per day also had decreased ethanol intake over time $\left[\mathrm{F}_{(2,16)}=12.4, P=0.0006\right]$. Post hoc analyses indicate a decrease from baseline ethanol intake only during the 4 days of MIFE administration [baseline: $3.2 \pm$ $0.4 \mathrm{~g} / \mathrm{kg}$ per day, $95 \% \mathrm{CI}(2.3,4.1) ; 56 \mathrm{mg} / \mathrm{kg}$ per day MIFE: $1.8 \pm 0.3 \mathrm{~g} / \mathrm{kg}$ per day, 95\% CI $\left.(1.2,2.5) ; P_{\mathrm{adj}}=0.0014\right]$ (Fig. 4B).

During the $30 \mathrm{mg} / \mathrm{kg}$ MIFE dosing, BEC was measured at baseline [day $1 ; 103 \pm 56 \mathrm{mg} / \mathrm{dl}, 95 \% \mathrm{CI}(59,146)]$, on the third MIFE dosing day [day 7; $59 \pm 49 \mathrm{mg} / \mathrm{dl}, 95 \% \mathrm{CI}(21,96)]$, and 4 days after the end of the MIFE dosing during Post-1 [day 12; $90 \pm 65 \mathrm{mg} / \mathrm{dl}, 95 \%$ CI (40, 140)] (Fig. 4C). An RM-ANOVA indicated a main effect of phase $\left[\mathrm{F}_{(1.9,15.2)}=8.2, P=0.0043\right]$. Correcting for multiple comparisons, BECs decreased during dosing (day 7) when compared with baseline $\left(P_{\text {adj }}=0.0082\right)$. To evaluate the effect of $56 \mathrm{mg} / \mathrm{kg}$ per day MIFE on BEC, samples were measured at baseline [day $-2 ; 106 \pm 80 \mathrm{mg} / \mathrm{dl}, 95 \% \mathrm{CI}$ $(45,168)$ ], the first day of MIFE dosing [day $5 ; 83 \pm 73 \mathrm{mg} / \mathrm{dl}$, 95\% CI $(27,139)$ ], the last day of MIFE dosing [day 8; $27 \pm$ $47 \mathrm{mg} / \mathrm{dl}, 95 \% \mathrm{CI}(-9,64)]$, and 6 days after the last dose [day 14; $91 \pm 40 \mathrm{mg} / \mathrm{dl}, 95 \%$ CI $(60,121)$ ] (Fig. 3D). An RM-ANOVA indicated a main effect of phase $\left[\mathrm{F}_{(1.8,14.6)}=6.2\right.$, $P=0.0124]$. Correcting for multiple comparisons, BECs had decreased on the last day of MIFE dosing (day 8) compared with baseline $\left(P_{\mathrm{adj}}=0.04\right)$ and between the last day of MIFE dosing (day 8) and BECs 6 days later (day 14), with BECs increasing when MIFE is no longer being administered $(P=0.0122)$. No differences were found between baseline and the 1st day of MIFE dosing (day 5).

Cortisol Response to MIFE Treatment. Cortisol increased during MIFE administration, similar to previous reports (Bertagna et al., 1984, 1994; Pal'chikova et al., 2016; Yuen et al., 2017). For $30 \mathrm{mg} / \mathrm{kg}$ per day MIFE, a mixed-effects 


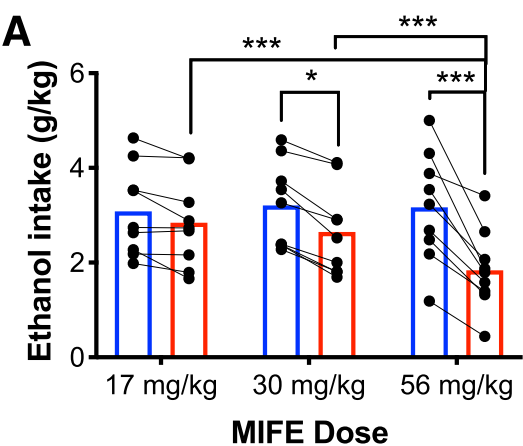

B

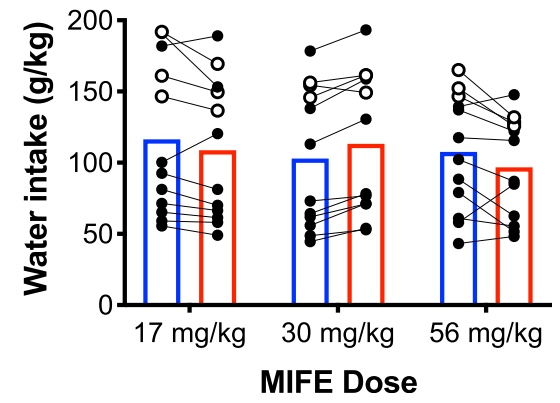

Fig. 3. Effect of MIFE on average ethanol (A) and water (B) intake during baseline (blue bars, 4 days immediately prior to each MIFE dose) and during MIFE administration (red bars, 4 days). Data represent individual ( $n=9$ drinkers, filled circles; $n=3$ controls, open circles) and average (bars). ${ }^{*} P<0.05$; $* * * P<0.001$. model revealed a main effect of time $\left[\mathrm{F}_{(3.30)}=9.81, P=0.0001\right]$ but not group. The interaction between time and group was significant $\left[\mathrm{F}_{(3,30)}=5.04, P=0.006\right.$; Fig. 5A $]$. Post hoc comparisons revealed that cortisol increased after the final dose of $30 \mathrm{mg} / \mathrm{kg}$ per day MIFE [day 9: $16.9 \pm 8.1 \mu \mathrm{g} / \mathrm{dl}, 95 \% \mathrm{CI}$ $(11.8,22.0)$ ] compared with pre-MIFE [day 5, immediately before the first daily dose: $12.1 \pm 4.9 \mu \mathrm{g} / \mathrm{dl}, 95 \%$ CI $(9.0,15.2)$; $P=0.0003$ ] but that this effect was driven by the ethanol-naïve controls $(P=0.0003)$. For $56 \mathrm{mg} / \mathrm{kg}$ per day MIFE, a mixedeffects model revealed a main effect of time $\left[\mathrm{F}_{(3.30)}=41.68, P<\right.$ 0.0001] but not group or an interaction (Fig. 5B). Post hoc comparisons revealed that cortisol after the final dose of $56 \mathrm{mg} / \mathrm{kg}$ per day MIFE [day 9: $44.7 \pm 14.2 \mu \mathrm{g} / \mathrm{dl}$, 95\% CI $(35.7,53.7)]$ increased when compared with pre-MIFE [day 5 , immediately before the first dose: $11.9 \pm 3.5 \mu \mathrm{g} / \mathrm{dl}, 95 \% \mathrm{CI}$ $(9.7,14.2) ; P<0.0001]$. The concentration of cortisol measured from plasma collected at 09:00 the morning after the final MIFE dose (day 9) positively correlated with the concentration of MIFE in the same sample ( $\mathrm{r}=0.86, P<0.0001$; Fig. $5 \mathrm{C})$. Additionally, there was a negative correlation between MIFE concentration measured on day 9 and the average percent change in ethanol intake during dosing $(r=-0.63, P=0.005$; Fig. 5D). With increasing MIFE concentrations, there was a greater decrease in average ethanol intake.
Because MIFE concentration in plasma was highly correlated with both plasma cortisol concentration and ethanol intake, we evaluated whether cortisol was mediating the effect of MIFE on ethanol intake (Fig. 6). Unlike covariates or moderators, mediators have a causal (in the current case, biologic) rationale between the independent and dependent variables. Specifically, MIFE increases cortisol. This is the indirect effect. Regression analysis indicated that MIFE concentration the morning after the final dose (day 9) predicted the change in ethanol intake during MIFE administration $(\beta=-0.132$, S.E. $=0.057, P=0.0 .035)$ and cortisol concentration on day $9(\beta=0.446$, S.E. $=0.056, P<0.0001)$. Cortisol was a predictor of the percent change in ethanol intake during MIFE administration $(\beta=-0.311$, S.E. $=$ $0.107, P=0.010)$. MIFE was no longer a predictor of percent change in ethanol intake after controlling for cortisol ( $\beta=$ 0.034, S.E. $=0.122, P=0.782$ ), consistent with full mediation. The mediation effect was tested using nonparametric bootstrap confidence intervals with the percentile method using 500 simulations. These average causal mediation effects show that the indirect coefficient was significant $[\beta=-0.166,95 \% \mathrm{CI}(-0.430,-0.02), P=0.036]$. The average direct effect when controlling for the mediator also supported mediation $[\beta=0.034,95 \% \mathrm{CI}(-0.17,0.32)$,
A

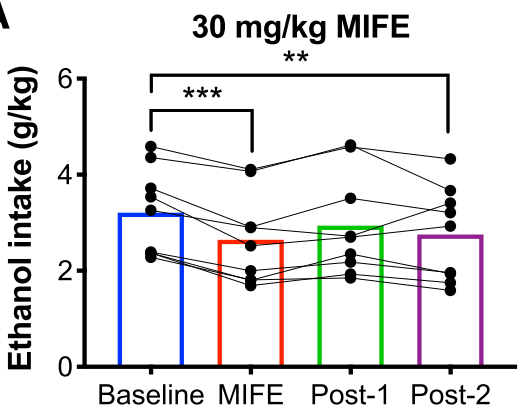

\section{C}

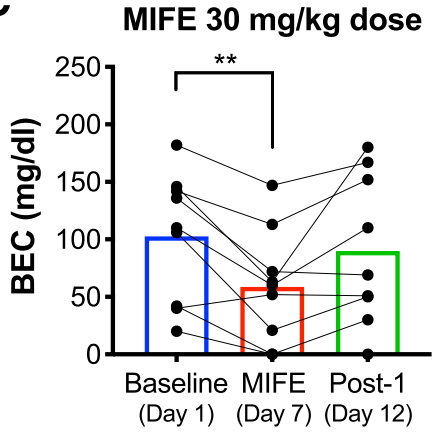

B

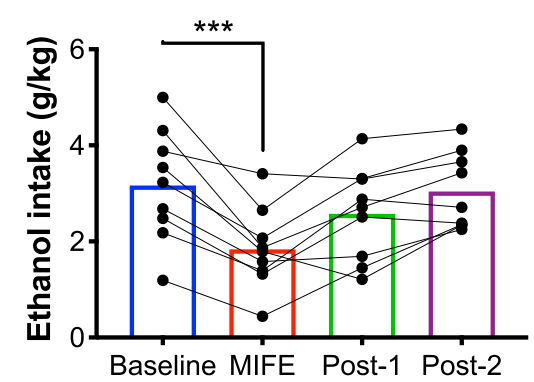

$56 \mathrm{mg} / \mathrm{kg}$ MIFE

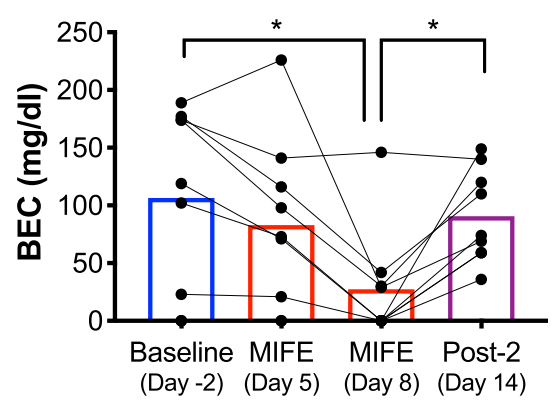

Fig. 4. The effect of MIFE on average daily ethanol intake and BEC across the phases shown in Fig. 1B. (A and B) Individual (circles) and average (bars) ethanol intake during experimental phases (4 days consecutive days) with 30 and $56 \mathrm{mg} / \mathrm{kg}$ MIFE. (C and D) Effect of 30 and $56 \mathrm{mg} / \mathrm{kg}$ on BEC. Bars represent the group average, individuals are represented by circles, and experimental day is shown in parenthesis below. $* P<0.05 ; * * P<0.01 ; * * * P<0.001$. 
A

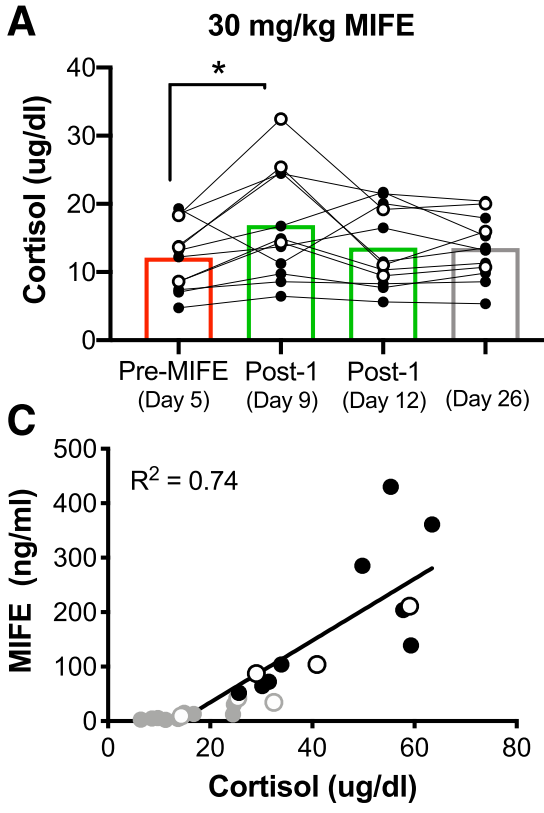

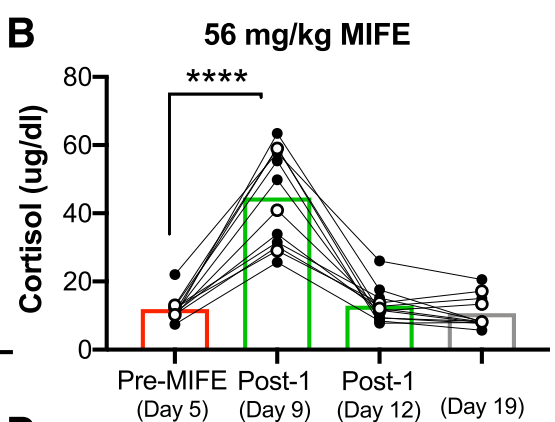

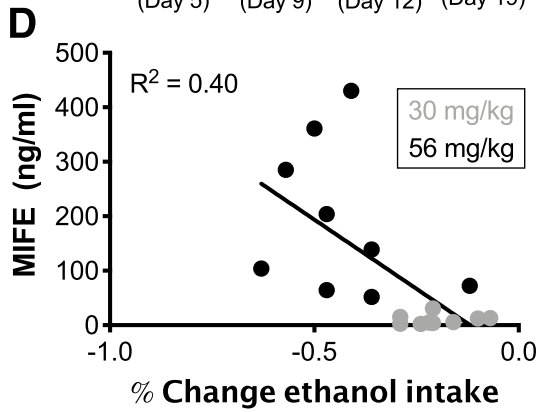

Fig. 5. Effect of MIFE on cortisol concentration measured in the AM during $30 \mathrm{mg} / \mathrm{kg}$ (A) and $56 \mathrm{mg} / \mathrm{kg}$ (B) dosing. Cortisol on day 5 was collected prior to the first MIFE dose and represents a baseline. (C) Relationship between cortisol and MIFE concentrations measured the morning after the final MIFE dose (day 9). (D) Relationship between MIFE concentration measured the morning after the final dose (day 9) and the average individual percent change in daily ethanol intake between baseline (days 1-4) and MIFE dosing (days $5-8$ ). Data represent individuals ( $n=9$ drinkers, $n=3$ controls). $* P<0.05 ; * * * P<0.001$
$P=0.74]$. The bootstrap analysis revealed that the proportion mediated to be $126 \%$, again supporting that the effect of MIFE on ethanol consumption was mediated by the increase in circulating cortisol.

Effect of MIFE on Relapse Drinking. Similar to previous cohorts, cortisol was elevated during forced abstinence, and all animals resumed drinking when ethanol is reintroduced (Cuzon Carlson et al., 2011; Allen et al., 2018). In these subjects, cortisol concentration was compared between open access (collected 1 week prior to the second abstinence phase) and abstinence (24 hours and 23 days into the second abstinence phase). A mixed-effects model revealed a main effect of phase $\left[\mathrm{F}_{(1.9,18.7)}=3.95, P=0.040\right]$ in which, compared with open access [relapse 1: $11.0 \pm 4.1$ $\mu \mathrm{g} / \mathrm{dl}, 95 \%$ CI $(8.4,13.6)]$, cortisol was higher during early [24 hours: $13.9 \pm 5.1 \mu \mathrm{g} / \mathrm{dl}, 95 \% \mathrm{CI}(10.7,17.2), P=0.017$ ] and protracted abstinence [23 days: $14.6 \pm 4.0 \mu \mathrm{g} / \mathrm{dl}, 95 \% \mathrm{CI}$ (12.0, 17.1), $P=0.033$, Fig. 7A].

We compared the time to consume $1.5 \mathrm{~g} / \mathrm{kg}$ ethanol and preference for ethanol on the 1st day of ethanol open access after the first and second abstinence phases to the limited relapses during early abstinence presented above. A mixed-effects model revealed a main effect of phase $\left[F_{(1.9}\right.$, $17.2)=16.5, P=0.0001]$ in which post hoc analysis revealed that the time to consume $1.5 \mathrm{~g} / \mathrm{kg}$ ethanol was higher after the first abstinence period [267.3 \pm 92.7 minutes, 95\% CI $(181.6,353.0)]$ compared with the pre-MIFE relapse $[82.8$ \pm 57.9 minutes, $95 \%$ CI $\left.(34.3,131.2) ; P_{\text {adj }}=0.0464\right]$, the post-MIFE relapse [20.2 \pm 6.8 minutes, $95 \%$ CI (14.5, 25.9); $P_{\mathrm{adj}}=0.0022$ ], and after the second abstinence phase $\left[76.2 \pm 94.6\right.$ minutes, 95\% CI $(-2.8,155.3) ; P_{\text {adj }}=0.0449$; Fig. 7B]. There was also a main effect of phase for preference $\left[\mathrm{F}_{(3,28)}=4.6, P=0.0099\right]$. Post hoc analysis revealed that preference for ethanol after the first abstinence phase was lower $[34.5 \% \pm 12.0 \%, 95 \%$ CI $(24.5,44.5)]$ when compared with both post-MIFE during abstinence $[61.0 \% \pm 17.5 \%$, 95\% CI $\left.(46.4,75.6) ; P_{\text {adj }}=0.0219\right]$ and the second abstinence phase $\left[61.4 \% \pm 18.9 \%, 95 \%\right.$ CI $(45.6,77.2) ; P_{\text {adj }}=0.0196$; Fig. 7C].

\section{Discussion}

MIFE, an antagonist at both the glucocorticoid (GR) and progesterone receptors, reduced ethanol consumption in this rhesus macaque model of long-term ethanol self-administration in a selective and dose-dependent manner. Extended use of MIFE is currently approved for cases of Cushing disease at a maximum of $20 \mathrm{mg} / \mathrm{kg}$ per day and is not recommended to exceed $600 \mathrm{mg} /$ day (about 8-10 mg/kg) in patients with hepatic impairment. MIFE has been suspected of causing drug-induced liver impairment (Funke and Rockey, 2019; Shah et al., 2019), In this study, the threshold effective dose regimen was $30 \mathrm{mg} / \mathrm{kg}$
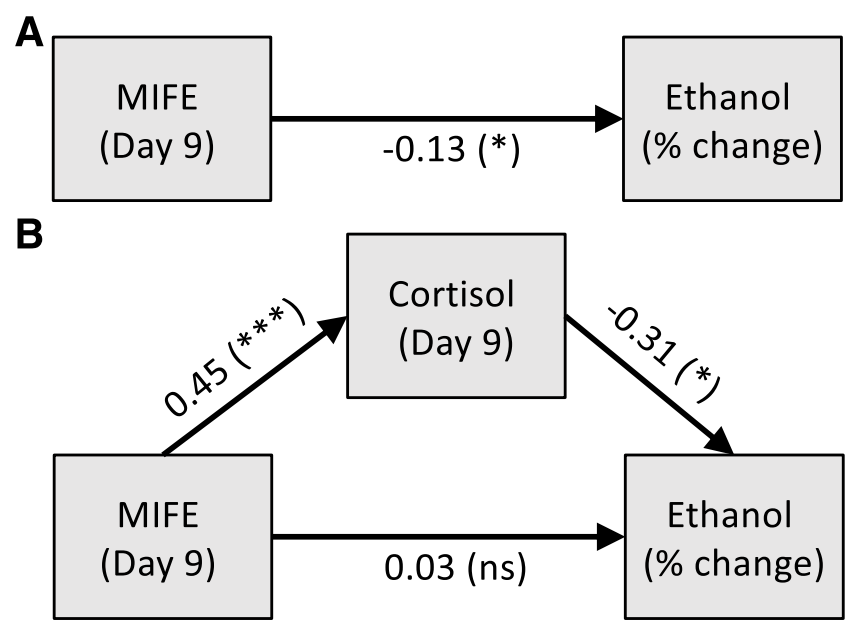

ACME: $-0.17(p=0.036)$

Fig. 6. Summary of mediation analysis. (A) The direct model of MIFE concentration the morning after the final dose (day 9) and the percent change in ethanol intake during MIFE (days 5-8) relative to baseline (days 1-4). (B) The mediation model with cortisol measured the morning after the final dose (day 9) as a mediator between MIFE concentration and percent change in ethanol self-administration. Path values correspond to unstandardized coefficients and significance. $* P<0.05$; $* * * P<0.0001$; ${ }^{\mathrm{ns}} P>0.05$. ACME, average causal mediation effect. 

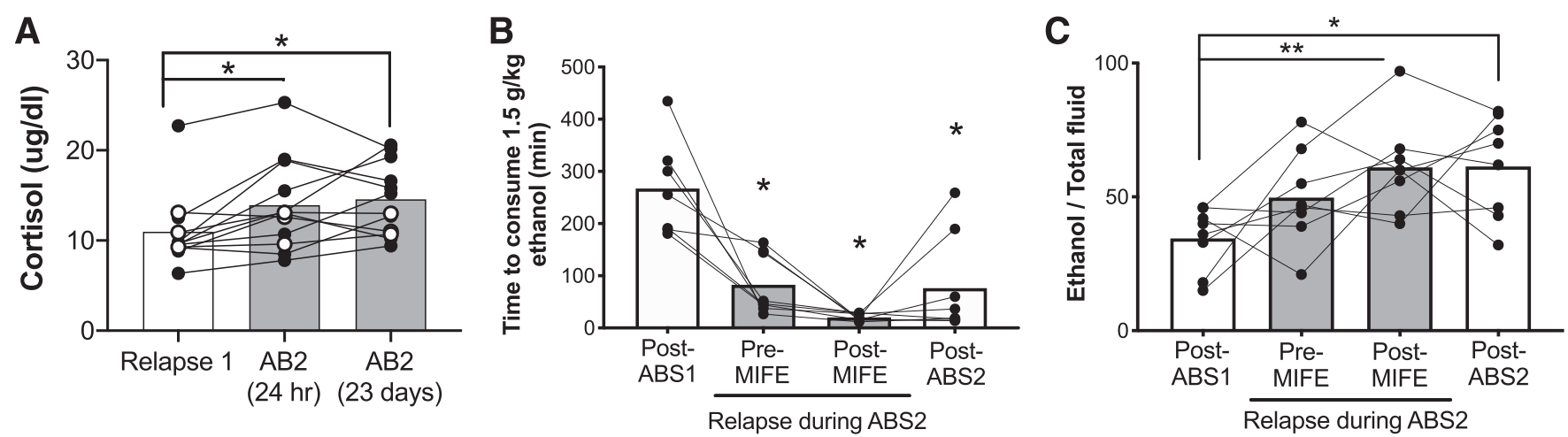

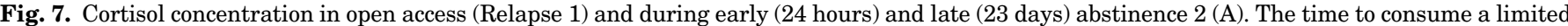

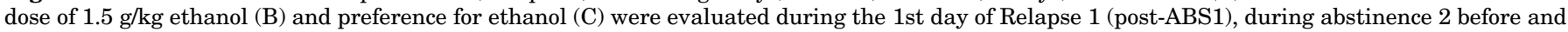

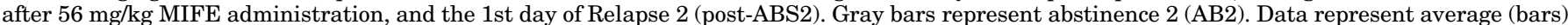
and individuals (closed circles: $n=8$ drinkers, open circles: $n=3$ controls). ${ }^{*} P<0.05 ; * * P<0.01$.

per day for 4 days. This dose decreased the average daily ethanol intake of nine monkeys from 3.2 to $2.3 \mathrm{~g} / \mathrm{kg}$ per day. In contrast, a study in baboons with limited daily access to ethanol and consuming about $1 \mathrm{~g} / \mathrm{kg}$ per day found that $30 \mathrm{mg} / \mathrm{kg} \mathrm{MIFE}$ was not effective in reducing ethanol self-administration (Holtyn and Weerts, 2019). A greater decrease in average daily intake was observed during $56 \mathrm{mg} / \mathrm{kg}$ of MIFE for 4 days, with average daily ethanol intake decreasing from 3.2 to $1.8 \mathrm{~g} / \mathrm{kg}$ per day, or $57 \%$ of baseline. This is approximately 12 to 13 drink equivalents cut to seven to eight drink equivalents. Although consumption remained high, the health benefits of reducing ethanol intake by almost half are clinically relevant (Charlet and Heinz, 2017; Pearson et al., 2017; Knox et al., 2018; Witkiewitz et al., 2018). One important caveat in the current study is the rapid return to baseline drinking when MIFE treatment ended. It remains to be determined whether longerterm administration of MIFE would have been more effective in reducing ethanol intake. However, long-term MIFE administration at these doses may increase the risk of adrenal insufficiency seen in clinical populations, such as Cushing syndrome, although we did not find evidence of this in our study. In this study, there were no observed changes in food or fluid intake that would indicate illness. Hypokalemia was not detected, and in fact potassium concentration increased after MIFE administration (Supplemental Fig. 1). Hypoglycemia resulting from MIFE administration has been reported (Humayun and Masding, 2016). Blood glucose decreased after $56 \mathrm{mg} / \mathrm{kg}$ MIFE when administered during open access but not during abstinence (Supplemental Fig. 2) Thus, the doses used here are a concern, particularly for extended treatment, and may be a barrier for use in a clinical setting. As stated above, the Food and Drug Administration has capped daily MIFE administration at $20 \mathrm{mg} / \mathrm{kg}$ per day (Castinetti et al., 2010; Sai et al., 2019). However, $600 \mathrm{mg} /$ day for 7 days was effective in reducing craving and the number of drinks per week in a small study of non-treatment-seeking, alcohol-dependent subjects (Vendruscolo et al., 2015).

One implication of the nonhuman primate studies is that the ability of MIFE to reduce ethanol drinking may be restricted to chronic heavy intakes greater than eight drink equivalents $(>2 \mathrm{~g} / \mathrm{kg})$ per day. That MIFE efficacy be restricted to heavy drinking is supported by rodent studies, in which MIFE was effective only in dependent animals whose intakes were higher than nondependent animals (Simms et al., 2012; Vendruscolo et al., 2012, 2015; RepunteCanonigo et al., 2015; Somkuwar et al., 2017). In addition, the two lightest drinkers in the current study increased their average daily ethanol intake after the $56 \mathrm{mg} / \mathrm{kg}$ MIFE treatment, indicating the possibility that some subjects may be vulnerable to a rebound effect. Together, these data suggest that there may be a minimum threshold of daily ethanol consumption for MIFE to be therapeutic and that below this threshold MIFE may be ineffective or contraindicated.

In terms of receptor specificity related to the decrease in alcohol intake, both GR and progesterone receptors act as ligand-dependent transcription factors and also have nongenomic actions mediated by second-messenger signaling pathways (Leonhardt et al., 2003; Lösel and Wehling, 2003; Rainville et al., 2019). Although MIFE is not a selective antagonist, the effects on ethanol drinking in rodents appear to be through GRs. Vendruscolo et al. (2015) demonstrated that MIFE reduced ethanol intake in dependent rats, and the effect was similar when CORT113176, a GR-specific antagonist, was administered. More recently, selective breeding for high binge-like ethanol intake drinking found in High Drinking in the Dark (HDID-1) mice was more sensitive to GR antagonism, as demonstrated by both MIFE and CORT113176 dosing (Savarese et al., 2020). Further, central GR expression is influenced by ethanol exposure and withdrawal in several limbic and reward regions (Roy et al., 2002; Vendruscolo et al., 2012; Repunte-Canonigo et al., 2015). However, there are mixed outcomes with site-specific MIFE administration, with both positive (Simms et al., 2012; Vendruscolo et al., 2012, 2015) and negative (RepunteCanonigo et al., 2015) outcomes when MIFE is delivered to the central nucleus of the amygdala and one report that MIFE administration to the ventral tegmental area and the nucleus accumbens decreased ethanol intake (Repunte-Canonigo et al., 2015). There are no studies in macaques directly addressing site-specific effects of MIFE, but the positive correlation between cortisol and circulating MIFE strongly suggests an effect through blocking GRs and inhibiting negative feedback to regulate cortisol levels in macaques. A further finding was that the increase in cortisol after MIFE administration was a mediating factor in decreasing ethanol drinking. Cortisol was not solely responsible for the change in intake, but the explained variance between MIFE and intake is greater when considering the effect of MIFE on cortisol. 
The analysis reported here supports a full mediation; however, additional research should be done to validate these findings. Of particular interest is whether cortisol mediates the effect of MIFE on ethanol intake in human alcoholics at doses that have been shown previously to reduce intake (Vendruscolo et al., 2015). Plasma cortisol also mediates the effect of MIFE on psychotic symptoms in a recent study (Block et al., 2018). Alternatively, MIFE-induced increases in cortisol may only be a biomarker of MIFE action at the GR and not directly related to reducing alcohol intake. This interpretation is not supported by studies of naloxone, a $\mu$-opioid receptor antagonist that decreases craving and drinks consumed and also increases cortisol (Wand et al., 2001; O’Malley et al., 2002; Hendershot et al., 2017). Together, MIFE and naloxone outcomes on ethanol drinking suggest that multiple mechanisms that increase cortisol may underlie positive outcomes in alcohol pharmacotherapy. However, this may be too simplistic of an explanation, as increased cortisol due to forced abstinence did not prevent relapse in this monkey model, and stressful events, which presumably increase cortisol, increase probability of a relapse in humans (Keyes et al., 2012; Wemm et al., 2019). Further, the relationship between cortisol and MIFE's effects on intake is counterintuitive, as they each have opposite effects on the GR.

An alternative explanation of MIFE-induced increases in cortisol mediating a decrease in alcohol intake is that cortisol has approximately 10-fold higher affinity for the mineralocorticoid receptor (MR). Under healthy, nonstressful basal conditions, most cortisol is bound to MRs. The role of MR in alcohol dependence and withdrawal has not been studied as extensively as GRs, but recent data suggest that MR may also be a promising pharmacologic target. In humans, the principal ligand for the MR, aldosterone, is positively correlated with craving and the number of drinks consumed (Leggio et al., 2008; Aoun et al., 2018). In this rhesus macaque model during long-term daily self-administration, circulating aldosterone was increased, and expression of the MR gene (NR3C2) in the central nucleus of the amygdala was negatively correlated with average daily intake (Aoun et al., 2018). In rodents, ethanol exposure did not alter MR expression (Vendruscolo et al., 2012); however, MR antagonism by spirolactone was effective in reducing ethanol seeking (Makhijani et al., 2018). Importantly, the balance between MR and GR is critical for maintaining homeostasis (de Kloet and Joëls, 2020). The indication that both long-term ethanol and repeated MIFE administration impact HPA axis activation and the balance of MR and GR warrants further investigation.

Repeated periods of forced abstinence (up to 34 days) after 12 months of daily access to alcohol in macaques reliably results in elevated cortisol and an immediate relapse to drinking once ethanol is reintroduced (Cuzon Carlson et al., 2011; Allen et al., 2018). Synaptic recordings from abstinent monkeys revealed increased excitatory activity onto parvocellular neurons in the hypothalamic paraventricular nucleus (PVN), the apex of the HPA axis, compared with ethanol-naïve controls (Jimenez et al., 2019). The frequency of excitatory events onto parvocellular neurons correlated with circulating cortisol and was normalized by applying $20 \mathrm{mM}$ (approximately $92 \mathrm{mg} / \mathrm{dl}$ ) ethanol. Thus, forced abstinence revealed an allostatic shift in glutamatergic activity within the PVN that was related to cortisol and influenced by ethanol. These synaptic studies demonstrate an important allostatic shift in activity at the apex of the stress response that may be driven by changes in GR expression or activity in the PVN and other limbic regions, such as the central nucleus of the amygdala (Simms et al., 2012; Vendruscolo et al., 2015). Furthermore, the rodent studies discussed previously and the data presented here demonstrate that ethanol dependence is necessary for MIFE to reduce ethanol consumption, suggesting that cycling between drinking and abstaining may expose vulnerability in the GR system that is targetable using GR-antagonists.

To test whether MIFE treatment could block relapse to alcohol drinking, the highest effective dose of MIFE $(56 \mathrm{mg} / \mathrm{kg}$ per day) was tested in a modified dosing of three daily doses during early abstinence. Under these conditions, MIFE did not block relapse. In fact, the time to consume $1.5 \mathrm{~g} / \mathrm{kg}$ decreased and preference for ethanol increased after MIFE administration in relapse. In rodents, MIFE blocks the postabstinence escalation of ethanol intake but also did not eliminate intake (Vendruscolo et al., 2012, 2015; Somkuwar et al., 2017). Given the decline in MIFE concentration the morning after the final dose (Fig. 2B) and the rapid return to drinking after dosing ended during open-access conditions (Fig. 4B), MIFE may have been more effective if administration had continued during the ethanol slip rather than ending the evening prior. However, these data do not suggest that tolerance to MIFE is responsible for the lack of effect in abstinence, as there were over 7 months (222 days) between the last MIFE dose during open access and abstinence.

In conclusion, epidemiologic data suggest that there have been similar rates of treatment seeking over the past several decades (Hasin et al., 2007; https://www.samhsa.gov/data/). Pharmacologic treatment options that are not tied to abstinence may help encourage a greater number of people to seek help (McGinty et al., 2015). The data presented here and a previous report on non-treatment-seeking, alcohol-dependent subjects (Vendruscolo et al., 2015) suggest MIFE may be an effective pharmacologic option for harm reduction in individuals who are not able, or interested, in abstinence. However, additional research is needed to determine whether MIFE can be an effective treatment in acute situations, similar to disulfiram, or would be safe for longterm administration.

\section{Acknowledgments}

The authors would like to acknowledge MicroConstants, Inc., in San Diego for measuring the plasma concentrations of mifepristone.

\section{Authorship Contributions}

Participated in research design: Hunt, Grant.

Conducted experiments: Shnitko, Newman, Diem, Vanderhooft.

Performed data analysis: Jimenez, Walter.

Wrote or contributed to the writing of the manuscript: Jimenez, Walter, Grant.

\section{References}

Adinoff B, Krebaum SR, Chandler PA, Ye W, Brown MB, and Williams MJ (2005a) Dissection of hypothalamic-pituitary-adrenal axis pathology in 1-month-abstinent alcohol-dependent men, part 1: adrenocortical and pituitary glucocorticoid responsiveness. Alcohol Clin Exp Res 29:517-527.

Adinoff B, Krebaum SR, Chandler PA, Ye W, Brown MB, and Williams MJ (2005b) Dissection of hypothalamic-pituitary-adrenal axis pathology in 1-month-abstinent alcohol-dependent men, part 2: response to ovine corticotropin-releasing factor and naloxone. Alcohol Clin Exp Res 29:528-537.

Adinoff B, Risher-Flowers D, De Jong J, Ravitz B, Bone GH, Nutt DJ, Roehrich L, Martin PR, and Linnoila M (1991) Disturbances of hypothalamic-pituitary-adrenal axis functioning during ethanol withdrawal in six men. Am J Psychiatry 148: 1023-1025. 
Adinoff B, Ruether K, Krebaum S, Iranmanesh A, and Williams MJ (2003) Increased salivary cortisol concentrations during chronic alcohol intoxication in a naturalistic clinical sample of men. Alcohol Clin Exp Res 27:1420-1427.

Allen DC, Gonzales SW, and Grant KA (2018) Effect of repeated abstinence on chronic ethanol self-administration in the rhesus monkey. Psychopharmacology (Berl) 235:109-120.

Aoun EG, Jimenez VA, Vendruscolo LF, Walter NAR, Barbier E, Ferrulli A, HaassKoffler CL, Darakjian P, Lee MR, Addolorato G, et al. (2018) A relationship between the aldosterone-mineralocorticoid receptor pathway and alcohol drinking: preliminary translational findings across rats, monkeys and humans. Mol Psychiatry 23:1466-1473.

Baker EJ, Farro J, Gonzales S, Helms C, and Grant KA (2014) Chronic alcohol selfadministration in monkeys shows long-term quantity/frequency categorical stability. Alcohol Clin Exp Res 38:2835-2843.

Becker HC (2012) Effects of alcohol dependence and withdrawal on stress responsiveness and alcohol consumption. Alcohol Res 34:448-458.

Bertagna X, Bertagna C, Luton JP, Husson JM, and Girard F (1984) The new steroid analog RU 486 inhibits glucocorticoid action in man. J Clin Endocrinol Metab $\mathbf{5 9}$ 25-28.

Bertagna X, Escourolle H, Pinquier JL, Coste J, Raux-Demay MC, Perles P, Silvestre L, Luton JP, and Strauch G (1994) Administration of RU 486 for 8 days in normal volunteers: antiglucocorticoid effect with no evidence of peripheral cortisol deprivation. J Clin Endocrinol Metab 78:375-380.

Blaine SK, Seo D, and Sinha R (2017) Peripheral and prefrontal stress system markers and risk of relapse in alcoholism. Addict Biol 22:468-478.

Blaine SK and Sinha R (2017) Alcohol, stress, and glucocorticoids: from risk to dependence and relapse in alcohol use disorders. Neuropharmacology 122:136-147.

Block TS, Kushner H, Kalin N, Nelson C, Belanoff J, and Schatzberg A (2018) Combined analysis of mifepristone for psychotic depression: plasma levels associated with clinical response. Biol Psychiatry 84:46-54.

Castinetti F, Conte-Devolx B, and Brue T (2010) Medical treatment of Cushing's syndrome: glucocorticoid receptor antagonists and mifepristone. Neuroendocrinology 92 (Suppl 1):125-130.

Charlet K and Heinz A (2017) Harm reduction-a systematic review on effects of alcohol reduction on physical and mental symptoms. Addict Biol 22:1119-1159.

Cippitelli A, Damadzic R, Hamelink C, Brunnquell M, Thorsell A, Heilig M, and Eskay RL (2014) Binge-like ethanol consumption increases corticosterone levels and neurodegneration whereas occupancy of type II glucocorticoid receptors with mifepristone is neuroprotective. Addict Biol 19:27-36.

Conley AJ, Pattison JC, and Bird IM (2004) Variations in adrenal androgen production among (nonhuman) primates. Semin Reprod Med 22:311-326.

Cuzon Carlson VC, Seabold GK, Helms CM, Garg N, Odagiri M, Rau AR, Daunais J, Alvarez VA, Lovinger DM, and Grant KA (2011) Synaptic and morphological neuroadaptations in the putamen associated with long-term, relapsing alcohol drinking in primates. Neuropsychopharmacology 36:2513-2528.

Daunais JB, Davenport AT, Helms CM, Gonzales SW, Hemby SE, Friedman DP, Farro JP, Baker EJ, and Grant KA (2014) Monkey alcohol tissue research resource: banking tissues for alcohol research. Alcohol Clin Exp Res 38:1973-1981.

de Kloet E. and Joëls M. (2020) Mineralocorticoid Receptors and Glucocorticoid Receptors in HPA Stress Responses During Coping and Adaptation. Oxford Research Encyclopedia of Neuroscience. Retrieved 9 Sep. 2020, from https://oxfordre. com/neuroscience/view/10.1093/acrefore/9780190264086.001.0001/acrefore9780190264086-e-266.

Funke K and Rockey DC (2019) Cholestatic drug-induced liver injury caused by mifepristone. Hepatology 69:2704-2706.

Grant BF, Goldstein RB, Saha TD, Chou SP, Jung J, Zhang H, Pickering RP, Ruan WJ, Smith SM, Huang B, et al. (2015) Epidemiology of DSM-5 alcohol use disorder: results from the national epidemiologic survey on alcohol and related conditions III. JAMA Psychiatry 72:757-766.

Grant KA, Leng X, Green HL, Szeliga KT, Rogers LS, and Gonzales SW (2008) Drinking typography established by scheduled induction predicts chronic heavy drinking in a monkey model of ethanol self-administration. Alcohol Clin Exp Res 32:1824-1838.

Hasin DS, Stinson FS, Ogburn E, and Grant BF (2007) Prevalence, correlates, disability, and comorbidity of DSM-IV alcohol abuse and dependence in the United States: results from the National Epidemiologic Survey on Alcohol and Related Conditions. Arch Gen Psychiatry 64:830-842.

Hendershot CS, Wardell JD, Samokhvalov AV, and Rehm J (2017) Effects of naltrexone on alcohol self-administration and craving: meta-analysis of human laboratory studies. Addict Biol 22:1515-1527.

Holtyn AF and Weerts EM (2019) Evaluation of mifepristone effects on alcoholseeking and self-administration in baboons. Exp Clin Psychopharmacol 27: 227-235.

Humayun MA and Masding M (2016) An unusual case of recurrent severe hypoglycemia in a woman with type 1 diabetes undergoing medically assisted abortion. Clin Diabetes 34:161-163.

Iranmanesh A, Veldhuis JD, Johnson ML, and Lizarralde G (1989) 24-hour pulsatile and circadian patterns of cortisol secretion in alcoholic men. $J$ Androl 10:54-63.

Jacquot C, Croft AP, Prendergast MA, Mulholland P, Shaw SG, and Little HJ (2008) Effects of the glucocorticoid antagonist, mifepristone, on the consequences of withdrawal from long term alcohol consumption. Alcohol Clin Exp Res 32 $2107-2116$.

Jimenez VA and Grant KA (2017) Studies using macaque monkeys to address excessive alcohol drinking and stress interactions. Neuropharmacology 122:127-135.

Jimenez VA, Herman MA, Cuzon Carlson VC, Walter NA, Grant KA, and Roberto M (2019) Synaptic adaptations in the central amygdala and hypothalamic paraventricular nucleus associated with protracted ethanol abstinence in male rhesus monkeys. Neuropsychopharmacology 44:982-993.

Keyes KM, Hatzenbuehler ML, Grant BF, and Hasin DS (2012) Stress and alcohol: epidemiologic evidence. Alcohol Res 34:391-400.
Knox J, Wall M, Witkiewitz K, Kranzler HR, Falk D, Litten R, Mann K, O’Malley SS, Scodes J, Anton R, et al; Alcohol Clinical Trials (ACTIVE) Workgroup (2018) Reduction in nonabstinent WHO drinking risk levels and change in risk for liver disease and positive AUDIT-C scores: prospective 3-year follow-up results in the U.S. general population. Alcohol Clin Exp Res 42:2256-2265.

Koenig HN and Olive MF (2004) The glucocorticoid receptor antagonist mifepristone reduces ethanol intake in rats under limited access conditions. Psychoneuroendocrinology 29:999-1003.

Leggio L, Ferrulli A, Cardone S, Miceli A, Kenna GA, Gasbarrini G, Swift RM, and Addolorato G (2008) Renin and aldosterone but not the natriuretic peptide correlate with obsessive craving in medium-term abstinent alcohol-dependent patients: a longitudinal study. Alcohol 42:375-381.

Leonhardt SA, Boonyaratanakornkit V, and Edwards DP (2003) Progesterone receptor transcription and non-transcription signaling mechanisms. Steroids 68 $761-770$

Litten RZ, Ryan ML, Falk DE, Reilly M, Fertig JB, and Koob GF (2015) Heterogeneity of alcohol use disorder: understanding mechanisms to advance personalized treatment. Alcohol Clin Exp Res 39:579-584.

Lösel R and Wehling M (2003) Nongenomic actions of steroid hormones. Nat Rev Mol Cell Biol 4:46-56.

Lovallo WR, Dickensheets SL, Myers DA, Thomas TL, and Nixon SJ (2000) Blunted stress cortisol response in abstinent alcoholic and polysubstance-abusing men. Alcohol Clin Exp Res 24:651-658.

Makhijani VH, Van Voorhies K, and Besheer J (2018) The mineralocorticoid receptor antagonist spironolactone reduces alcohol self-administration in female and male rats. Pharmacol Biochem Behav 175:10-18.

McGinty EE, Goldman HH, Pescosolido B, and Barry CL (2015) Portraying mental illness and drug addiction as treatable health conditions: effects of a randomized experiment on stigma and discrimination. Soc Sci Med 126: $73-85$

O'Malley SS, Krishnan-Sarin S, Farren C, Sinha R, and Kreek MJ (2002) Naltrexone decreases craving and alcohol self-administration in alcohol-dependent subjects and activates the hypothalamo-pituitary-adrenocortical axis. Psychopharmacology (Berl) 160:19-29.

Pal'chikova NA, Kuznetsova NV, Selyatitskaya VG, Cherkasova OP, and Kuz'mina OI (2016) Effects of intraperitoneal administration of mifepristone on glucocorticoid status of experimental animals. Bull Exp Biol Med 161:257-260.

Pearson MR, Bravo AJ, Kirouac M, and Witkiewitz K (2017) The search for an elusive cutoff remains: problems of binary classification of heavy drinking as an endpoint for alcohol clinical trials. Drug Alcohol Depend 171:91-96.

Rainville JR, Weiss GL, Evanson N, Herman JP, Vasudevan N, and Tasker JG (2019) Membrane-initiated nuclear trafficking of the glucocorticoid receptor in hypothalamic neurons [published correction appears in Steriods (2020) 155:108382]. Steroids 142:55-64.

Repunte-Canonigo V, Shin W, Vendruscolo LF, Lefebvre C, van der Stap L, Kawamura T, Schlosburg JE, Alvarez M, Koob GF, Califano A, et al. (2015) Identifying candidate drivers of alcohol dependence-induced excessive drinking by assembly and interrogation of brain-specific regulatory networks. Genome Biol 16:68.

Reus VI, Fochtmann LJ, Bukstein O, Eyler AE, Hilty DM, Horvitz-Lennon M Mahoney J, Pasic J, Weaver M, Wills CD et al (2018) The American Psychiatric Association practice guideline for the pharmacological treatment of patients with alcohol use disorder. Am J Psychiatry 175:86-90.

Rotter A, Biermann T, Amato D, Schumann G, Desrivieres S, Kornhuber J, and Müller CP (2012) Glucocorticoid receptor antagonism blocks ethanol-induced place preference learning in mice and attenuates dopamine D2 receptor adaptation in the frontal cortex. Brain Res Bull 88:519-524.

Roy A, Mittal N, Zhang H, and Pandey SC (2002) Modulation of cellular expression of glucocorticoid receptor and glucocorticoid response element-DNA binding in rat brain during alcohol drinking and withdrawal. J Pharmacol Exp Ther 301: 774-784.

Sai K, Lal A, Lakshmi Maradana J, Velamala PR, and Nitin T (2019) Hypokalemia associated with mifepristone use in the treatment of Cushing's syndrome. Endocrinol Diabetes Metab Case Rep 2019:19-0064.

Savarese AM, Ozburn AR, Metten P, Schlumbohm JP, Hack WR, LeMoine K, Hunt H, Hausch F, Bauder M, and Crabbe JC (2020) Targeting the glucocorticoid receptor reduces binge-like drinking in High Drinking in the Dark (HDID-1) mice. Alcohol Clin Exp Res 44:1025-1036.

Shah I, Putnam T, Daugherty E, Vyas N, and Chuang KY (2019) Mifepristone: an uncommon cause of drug-induced liver injury. Gastroenterol Res 12:181-184.

Sharrett-Field L, Butler TR, Berry JN, Reynolds AR, and Prendergast MA (2013) Mifepristone pretreatment reduces ethanol withdrawal severity in vivo. Alcohol Clin Exp Res 37:1417-1423.

Shnitko TA, Gonzales SW, Newman N, and Grant KA (2020) Behavioral flexibility in alcohol-drinking monkeys: the morning after. Alcohol Clin Exp Res 44:729-737.

Shnitko TA, Liu Z, Wang X, Grant KA, and Kroenke CD (2019) Chronic alcohol drinking slows brain development in adolescent and young adult nonhuman primates. eNeuro 6:ENEURO.0044-19.2019.

Simms JA, Haass-Koffler CL, Bito-Onon J, Li R, and Bartlett SE (2012) Mifepristone in the central nucleus of the amygdala reduces yohimbine stress-induced reinstatement of ethanol-seeking. Neuropsychopharmacology 37:906-918.

Somkuwar SS, Vendruscolo LF, Fannon MJ, Schmeichel BE, Nguyen TB, Guevara J, Sidhu H, Contet C, Zorrilla EP, and Mandyam CD (2017) Abstinence from prolonged ethanol exposure affects plasma corticosterone, glucocorticoid receptor signaling and stress-related behaviors. Psychoneuroendocrinology 84 $17-31$

Swift RM and Aston ER (2015) Pharmacotherapy for alcohol use disorder: current and emerging therapies. Harv Rev Psychiatry 23:122-133.

Tingley D, Yamamoto T, Hirose K, Keele L, and Imai K (2014) Mediation: R package for causal mediation analysis. J Stat Softw 59:1-38. 
Vendruscolo LF, Barbier E, Schlosburg JE, Misra KK, Whitfield TW Jr., Logrip ML, Rivier C, Repunte-Canonigo V, Zorrilla EP, Sanna PP, et al. (2012) Corticosteroiddependent plasticity mediates compulsive alcohol drinking in rats. J Neurosci 32 7563-7571.

Vendruscolo LF, Estey D, Goodell V, Macshane LG, Logrip ML, Schlosburg JE, McGinn MA, Zamora-Martinez ER, Belanoff JK, Hunt HJ, et al. (2015) Glucocorticoid receptor antagonism decreases alcohol seeking in alcohol-dependent individuals. J Clin Invest 125:3193-3197.

Vivian JA, Green HL, Young JE, Majerksy LS, Thomas BW, Shively CA, Tobin JR, Nader MA, and Grant KA (2001) Induction and maintenance of ethanol selfadministration in cynomolgus monkeys (Macaca fascicularis): long-term characterization of sex and individual differences. Alcohol Clin Exp Res 25:1087-1097.

Wand G, McCaul ME, Gotjen D, Reynolds J, and Lee S (2001) Confirmation that offspring from families with alcohol-dependent individuals have greater hypothalamic-pituitary-adrenal axis activation induced by naloxone compared with offspring without a family history of alcohol dependence. Alcohol Clin Exp Res 25:1134-1139.

Weerts EM, Fantegrossi WE, and Goodwin AK (2007) The value of nonhuman primates in drug abuse research. Exp Clin Psychopharmacol 15:309-327.
Wemm SE, Larkin C, Hermes G, Tennen H, and Sinha R (2019) A day-by-day prospective analysis of stress, craving and risk of next day alcohol intake during alcohol use disorder treatment. Drug Alcohol Depend 204:107569.

Witkiewitz K, Kranzler HR, Hallgren KA, O'Malley SS, Falk DE, Litten RZ, Hasin DS, Mann KF, and Anton RF (2018) Drinking risk level reductions associated with improvements in physical health and quality of life among individuals with alcohol use disorder. Alcohol Clin Exp Res 42:2453-2465.

Witkiewitz K, Litten RZ, and Leggio L (2019) Advances in the science and treatment of alcohol use disorder. Sci Adv 5:eaax4043.

Yuen KCJ, Moraitis A, and Nguyen D (2017) Evaluation of evidence of adrenal insufficiency in trials of normocortisolemic patients treated with mifepristone. $J$ Endocr Soc 1:237-246.

Address correspondence to: Dr. Kathleen A. Grant, Oregon National Primate Research Center, Oregon Health \& Science University, 505 NW 185th Avenue, L584, Beaverton, OR 97006-3448. E-mail: grantka@ohsu.edu 